\title{
Ein Aufsteiger als König von Böhmen. Von der Ablehnung ZUR ANERKENNUNG: GEORG VON PODIEBRAD UND DIE FÜRSTENTREFFEN AM BEGINN SEINER KÖNIGSHERRSCHAFT 1459-62
}

\author{
UWE TRESP \\ Universität Potsdam
}

ZuSAMMENFASSUNG: Im Jahre 1458 wurde der böhmische Adlige Georg von Podiebrad zum König von Böhmen gewählt. Allerdings wurde die Legitimation seines Königtums durch Kaiser Friedrich III., König Kasimir IV. von Polen und viele deutsche Fürsten bestritten. In einer Reihe persönlicher Treffen mit seinen Gegnern gelang es Podiebrad aber bis 1462, von diesen vollständige Anerkennung zu erlangen. Dieser Aufsatz fragt, welche Rolle dabei die symbolische Kommunikation durch Rituale und öffentliche Inszenierungen, wie sie bei mittelalterlichen Herrschertreffen üblich waren, spielten.

Schlagworte: Mittelalter, Deutschland, Königreich Böhmen, Herrschertreffen, Rituale.

AbSTRACT: In 1458 the Czech nobleman George of Poděbrady was elected to be king of Bohemia. But emperor Frederick III, the Polish king Kasimir IV and many German princes refused to recognize his royal legality. Until 1462, with a number of personal meetings, George of Poděbrady succeeded in obtaining recognition from his opponents. This paper asks for the influence of symbolic communication by rituals and public stages, as they were usual in medieval policy, on these meetings.

Keywords: Middle Ages, Germany, Kingdom of Bohemia, meetings of rulers, rituals. 


\section{DeR UMSTRITTENE KÖNIG}

m 2. März 1458 wurde Georg von Podiebrad (Jiří z Poděbrad, 1420-1471)
Adeligen Rathaus der Altstadt Prag durch eine Versammlung von böhmischen
die Nachfolge des im November 1457 ohne eigene Nachkommen jung
verstorbenen Habsburgers Ladislaus Postumus ("1440) an.
Die überraschende Wahl Podiebrads war von Anfang an heftig umstritten,
weil der Wahlakt und der Gewählte in den Augen ihrer Gegner mit deutlichen
Makeln behaftet waren. Besondere Brisanz besaß dabei die Glaubensfrage.
Georg von Podiebrad war ein Anhänger der hussitischen Reformation und
wurde von seinen innen- und außenpolitischen Gegnern daher für einen
Ketzer gehalten. Ein weiterer Makel war die Herkunft des neuen Königs. Georg
entstammte einer ostböhmischen Adelsfamilie. Mit sicherem Machtinstinkt
und Zielstrebigkeit hatte er die instabile Situation des Königreichs Böhmen in
Folge der Hussitischen Revolution (1420-1434) für seinen politischen Aufstieg
genutzt. Mit Makeln behaftet war auch der Prager Wahlakt im Frühjahr 1458,
eine durchsichtige Inszenierung der Anhänger Podiebrads, die viele formale
Kriterien einer böhmischen Königswahl verletzte.
Besonders gefährlich für die Anerkennung der umstrittenen Königswahl
und damitnichtzuletzt auch für den friedlichen Bestand der Staatskonstruktion
der Böhmischen Krone war die fehlende dynastische Legitimation des neuen
Königs. Mit der Wahl eines einheimischen Adeligen ohne fürstliche Herkunft
hatten die böhmischen Wähler gleich mehrere mächtige benachbarte
Herrscherhäuser verprellt, die Rechte auf den böhmischen Thron geltend
machten. ${ }^{2}$ An erster Stelle konnten die verschiedenen Linien des Hauses
Habsburg Anspruch auf das Erbe ihres Vetters Ladislaus Postumus erheben,
sei es auf der Grundlage der luxemburgisch-habsburgischen Erbverbrüderung
von $1364 / 1366$ oder als nächste männliche Verwandte im Rahmen der

1. Zu Biographie, politischer Karriere und Königsherrschaft des Georg von Podiebrad: Petr Čornej und Milena Bartlová: Velké dějiny zemí Koruny české, Bd. 6 (1437-1526), Praha, 2007 (zur Königswahl S. 152-162); FrantišEK ŠMAhel: Die Hussitische Revolution, Bd. 3 (MGH, Schriften 43,3), Hannover, 2002, S. 1782-1860; Frederick George Heymann: George of Bohemia, King of Heretics, Princeton, 1965 (zur Königswahl S. 147-160); OtaKar OdložIlík: The Hussite King. Bohemia in European Affairs 1440-1471, New Brunswick, 1965 (zur Königswahl S. 89-95); Rudolf UrbáneK: Věk poděbradský, 4 Bde. (České dějiny III), Praha, 1915-1962 (zur Königswahl Bd. 3, S. 223-371). Speziell zu Verlauf, Hintergründen und Folgen der Königswahl von 1458: Adolf Bachmann: «Ein Jahr böhmischer Geschichte. Georgs von Podiebrad Wahl, Krönung und Anerkennung», in: Archiv für österreichische Geschichte 54 (1876), S. 37-174, hier S. 91-98; Ders.: «Neues über die Wahl König Georgs von Böhmen», in: Mittheilungen des Vereines für Geschichte der Deutschen in Böhmen 33 (1894/95), S. 1-16; Ders.: Geschichte Böhmens (Geschichte des europäischen Staaten 31), Bd. 2, Gotha, 1905, S. 466-489; Rudolf URBÁNeK: «Volba Jiř́iho z Poděbrad za krále českého», in: Sborník př́spěvků k dějinám hlavního města Prahy 5/2 (1932), S. 593-766, bes. S. 723757. Die wichtigsten Quellen zur Wahl sind gesammelt in: $O$ volbě Jiř́ho $z$ Poděbrad za krále českého 2. brezna 1458, hg. von Rudolf UrbáneK, Praha, 1958.

2. Die Frage der böhmischen Thronrechte nach dem Tod König Ladislaus' ist in der älteren Literatur bereits ausführlich diskutiert worden: BaChmann, Ein Jahr, S. 59-74; Ders., Geschichte Böhmens, S. 466470; UrbáneK, Volba, S. 642-674. 
habsburgischen Hausordnung. ${ }^{3}$ Da seit 1348 im Königreich Böhmen auch eine weibliche Erbfolge möglich war, ${ }^{4}$ kamen für die Nachfolge des Ladislaus Postumus auch seine beiden älteren Schwestern Anna und Elisabeth mit ihren Familien in Frage. Die erstgeborene Anna von Habsburg ("1432) hatte 1446 Herzog Wilhelm III. von Sachsen, Landgrafen von Thüringen, aus dem ambitionierten deutschen Fürstenhaus Wettin geheiratet. Ihre jüngere Schwester Elisabeth von Habsburg ("1437) war seit 1454 die Gemahlin König Kasimirs IV. von Polen. Damit gehörte auch das polnisch-litauische Herrscherhaus der Jagiellonen zum Kreis der potentiellen Anwärter auf den böhmischen Thron.

Tatsächlich waren es dann aber nur Herzog Wilhelm von Sachsen und der französische König Karl VII. für einen seiner Söhne, die sich im Frühjahr 1458 energisch um die Krone von Böhmen bewarben. ${ }^{5}$ Der Ablauf der Prager Wahlversammlung ließ ihnen jedoch von vornherein keine Chance. Ohne Rücksicht auf vorhandene legitime Ansprüche der mit Ladislaus Posthumus verwandten Fürsten und auf formale Einwände gegen den Wahlakt beharrte der böhmische Adel auf sein vermeintliches Recht der freien Königswahl. Diese trotzige Haltung aber führte zu einer umso stärkeren Ablehnung des auf diese Weise gewählten Königs durch die Habsburger, die Wettiner und die mit ihnen verwandten deutschen Fürsten. In ihren Augen war Georg von Podiebrad ein zum Königtum unwürdiger Parvenü, ein Usurpator auf dem böhmischen Thron. ${ }^{6}$

3. Codex juris Bohemici II/1, hg. von Hermenegild JirečEK, Prag/Leipzig, 1896, Nr. 531-538. Auf die Erbverbrüderung bezog sich ein relativ kraftlos vorgebrachter Anspruch der Erzherzöge Albrecht VI. von Österreich und Sigismund von Tirol: Urkundliche Beiträge zur Geschichte Böhmens und seiner Nachbarländer im Zeitalter Georg's von Podiebrad (1450-1471), hg. von_Franz PALACKy, Wien, 1860 (Fontes rerum austriacarum, Zweite Abtheilung. Diplomataria et acta. Bd. 20), Nr. 152. Gleichfalls bezog sich darauf - angeblich - der böhmische Herr Jan von Rosenberg, als er sich zunächst der Wahl Georgs von Podiebrad verweigerte. Siehe: Urkundliche Nachträge zur österreichisch-deutschen Geschichte im Zeitalter Kaiser Friedrichs III., hg. von ADOLF BACHMANN, Wien, 1892 (Fontes rerum austriacarum. Oesterreichische Geschichts-Quellen. Zweite Abtheilung. Diplomata et Acta 46), Nr. 1.

4. Siehe dazu die Privilegien König Karls IV. von 1348, 1349 und 1355: Archivum Coronae regni Bohemiae, Bd. I/2, hg. von VÁClav HrubÝ, Praha, 1928, Nr. 51 und Nr. 124; Regesta diplomatica nec non epistolaria Bohemiae et Moraviae, Bd. 6, hg. von BedřICH MendL, Praha, 1928, Nr. 126.

5. Neben der bereits in Anm. 1 genannten Literatur ausführlich zur Thronkandidatur Herzog Wilhelms: Rudolf UrbáneK: «Kandidatura Viléma Saského na český trůn», in: Ders.: Dvě studie o době poděbradské (Spisy Filosofické fakulty Masarykovy university v Brně 27), Brno, 1929, S. 142-294.

6. Stellvertretend für die damals unter den Gegnern Podiebrads vorherrschende Meinung steht die Aussage eines deutschen Fürsten (vermutlich Markgraf Albrechts von Brandenburg) in einem Protestschreiben an Kaiser Friedrich III.: Girszig von Kunstad, der vor des genanten konig Laszlaes loblicher gedechtniss diener und gubernator gewest vnd eyns irrigen, vnreynen glaubens sey, durch ein vermessene, verechte vnd verkerliche wale fur konig zu Behemen habe ufrucken lassen über loblich alt herkomen, friheit, gewonheit vnd verschriebungen, in vorsatze vnd meinunge, die genanten frauwen Annan, sin gemaheln (Anna von Österreich, die Schwester König Ladislaus' und Gemahlin Wilhelms von Sachsen), vnd yn (Herzog Wilhelm) von yren wegin yrer gotlichen anerstorben gerechtigkeit zu entsetzen vnd zu enterben (Urkunden und Actenstücke zur österreichischen Geschichte im Zeitalter Kaiser Friedrichs III. und König Georgs von Böhmen (1440-1471), hg. von Adolf Bachmann (Fontes rerum Austriacarum. Oesterreichische GeschichtsQuellen, Zweite Abtheilung. Diplomataria et acta. Bd. 42), Wien, 1879, Nr. 168. Ein gleich lautendes Schreiben Markgraf Johanns von Brandenburg an Kaiser Friedrich III.: Urkunden und Beilagen zum Kampfe der wittelsbachischen und brandenburgischen Politik in den Jahren 1459 bis 1465 (Urkunden und Beilagen 
Trotz dieser Voraussetzungen gelang es Georg von Podiebrad in den folgenden Jahren, seinem Königtum nach innen und außen hin vollständige Anerkennung zu verschaffen, wenn auch nur vorläufig. ${ }^{7}$ Dabei profitierte er von der schwierigen politischen Situation seiner Gegner. Die Habsburger fochten nach dem Tod des Ladislaus Postumus einen innerdynastischen Erbfolgekrieg aus. ${ }^{8}$ Unter den deutschen Fürsten entwickelte sich eine polarisierende Rivalität unter der jeweiligen Systemführerschaft der Wittelsbacher und der Zollern, die sich schließlich im Süddeutschen Fürstenkrieg (1459-1462) entladen sollte und in deren Sog auch die Wettiner als Verbündete der Zollern gerieten. ${ }^{9}$ Und der polnische König war im Dreizehnjährigen Krieg (14541466) gegen den Deutschen Orden in Preußen gebunden. ${ }^{10}$ Damit waren nicht nur alle gefährlichen Thronrivalen Podiebrads abgelenkt. Angesichts der zahlreichen Kriege und drohenden Konflikte in Mitteleuropa begann sich die Stellung der Böhmischen Krone im Konzert der regionalen Mächte zu ändern. In Folge der Hussitischen Revolution war Böhmen zwischenzeitlich von einer hegemonialen Vormacht zum Außenseiter im Heiligen Römischen Reich herabgesunken. Ab der Mitte des 15. Jahrhunderts konnte dies aber zum Teil wieder dadurch ausgeglichen werden, dass es zur gefürchteten Kriegsmacht und zum führenden Söldnermarkt in Mitteleuropa avancierte. ${ }^{11}$

zur Geschichte Herzogs Albrecht IV. von Bayern und seiner Zeit I/1), hg. von Gustav FreiHerR voN Hasselholdt-Stockheim, Leipzig, 1865, Nr. X). - Siehe dazu Uwe Tresp, «Das Fürstentreffen von Eger und die sächsisch-böhmischen Beziehungen um 1459», in: ANDRÉ ThIEME und Uwe TrESP (Hrsg.): Eger 1459. Fürstentreffen zwischen Sachsen, Böhmen und ihren Nachbarn: Dynastische Politik, fürstliche Repräsentation und kulturelle Verflechtung, Wettin, 2011 (Saxonia 13), S. 67-128, hier S. 89-94.

7. Ab 1465 geriet sein Königtum durch eine böhmische Adelsfronde, eine päpstliche Bannbulle 1466 und die Wahl des Ungarn Matthias Corvinus zum böhmischen Gegenkönig 1469 erneut in erhebliche Schwierigkeiten. Vgl. dazu Čornej/Bartlová, Velké dějiny, S. 200-272; Heymann, George of Bohemia, S. 384-585.

8. Alois Niederstätter: 1400-1522: Das Jahrhundert der Mitte. An der Wende vom Mittelalter zur Neuzeit (Österreichische Geschichte), Wien, 1996, S. 250-255; KARL-FriedriCH KRIEgER: Die Habsburger im Mittelalter. Von Rudolf I. bis Friedrich III., Stuttgart/Berlin/Köln, 1994, S. 195-208; HEINRICH VON ZeissberG: «Der österreichische Erbfolgestreit nach dem Tode des Königs Ladislaus Postumus (14571458) im Lichte der habsburgischen Hausverträge», in: Archiv für österreichische Geschichte 58 (1879), S. 1-170. - Zur ambivalenten Haltung Kaiser Friedrichs III. gegenüber dem neu gewählten böhmischen König siehe: IVAN HLAvÁČEK: «Beiträge zur Erforschung der Beziehungen Friedrichs III. zu Böhmen bis zum Tode Georgs von Podiebrad (†1471)», in: Kaiser Friedrich III. (1440-1493) in seiner Zeit. Studien anläßlich des 500. Todestages am 19. August 1493/1993, hg. von PAUl-JoAChim Heinig, Köln/Weimar/ Wien, 1993, S. 279-298, hier S. 292 f.

9. Mario Müller: «Die diplomatische Kärrnerarbeit des Vermittlers. Markgraf Albrecht von Brandenburg auf dem Egerer Fürstentreffen 1459», in: Thieme/Tresp (Hrsg.), Eger 1459, S. 178-226; Jörg SCHWARZ: «Die Wittelsbacher und der Tag von Eger 1459», in: ebenda, S. 227-240; GABriel Zeilinger: «Gruppenbild mit Markgraf. Albrecht „Achilles“ von Brandenburg (1414-1486), die Reichsfürsten seiner Zeit und die Frage nach zeitgenössischer und historiographischer Prominenz», in: Fürsten an der Zeitenwende zwischen Gruppenbild und Individualität, hg. von Oliver Auge, Ralf-GunNar Werlich und Gabriel Zeilinger, Ostfildern 2009 (Residenzenforschung 22), S. 291-307.

10. MARIAN Biskup: Trzynastoletnia wojna z Zakonem Krzyżackim 1454-1466, Warszawa, 1967.

11. Ursächlich dafür waren das von den Hussiten ausgehende innovative böhmische Kriegswesen und ein besonders beutegieriger Adel. Siehe dazu Uwe Tresp: Söldner aus Böhmen. Im Dienst deutscher Fürsten: Kriegsgeschäft und Heeresorganisation im 15. Jahrhundert (Krieg in der Geschichte 19), Paderborn, 2004; Ders.: «Die “Quelle der Kriegsmacht”. Böhmen als spätmittelalterlicher Söldnermarkt», in: Rückkehr der Condottieri? Krieg und Militär zwischen staatlichem Monopol und Privatisierung: Von der Antike bis zur 
Das Königreich Böhmen - und mit ihm sein Herrscher - wurde zum gesuchten Bündnispartner oder gefürchteten Gegner der Kriegsparteien.

\section{HERRSCHERTREFFEN ALS BÜHNE SYMBOLISCHER KOMMUNIKATION}

Vor diesem Hintergrund fanden in den ersten Jahren seiner Herrschaft verschiedene Treffen König Georgs mit benachbarten Fürsten statt. Besonders interessant sind dabei Begegnungen, bei denen der von seinen Gegnern als illegitimer Herrscher geschmähte König erstmals nach der Thronbesteigung persönlich auf Rivalen traf, die ihm die Anerkennung noch verweigerten. Zur Inszenierung solcher Herrschertreffen gehörten zahlreiche zeremonielle Akte, die im Mittelalter vor großer Öffentlichkeit stattfanden: Begrüßungsrituale, feierliche Einzüge in Städte, Prozessionen, festliche Lustbarkeiten, inszenierte Mahlzeiten, rituelle Beschenkungen und Verabschiedungen, um nur einige wichtige Punkte des üblichen Programms zu nennen. Sie alle hatten gemein, dass sie Bestandteile eines komplexen Handlungsablaufs öffentlicher Herrscherrepräsentation waren und im Rahmen allgemein akzeptierter Regeln verliefen. Damit aber stellten sie zugleich soziale Eindeutigkeit her. Sie schufen eine Situation, in der die Beteiligten öffentlich „Farbe bekennen“ mussten über ihr gegenseitiges Verhältnis - und zwar mit einer Verbindlichkeit, die nicht hinter der von Eiden oder Verträgen zurückstand. Die öffentlichen Akte im Rahmen von Herrschertreffen gehören damit zu jenen regelhaften oder gar regelgeleiteten Ritualen, mit denen in vormodernen Gesellschaften soziale Ordnung gestiftet oder bestätigt wurde. ${ }^{12}$

Gegenwart, hg. von Stig Förster, Christian Jansen und Günther Kronenbitter, Paderborn, 2010 (Krieg in der Geschichte 57), S. 43-61; Ders.: «Böhmen als Söldnermarkt des ausgehenden Mittelalters», in: Krieg in der europäischen Neuzeit, hg. von Thomas Kolnberger und Ilja Steffelbauer, Wien, 2010 (Krieg und Gesellschaft 3), S. 36-57.

12. In den letzten Jahrzehnten hat sich in der internationalen und deutschsprachigen Forschung eine breite Hinwendung zur Erforschung von symbolischer Kommunikation und Ritualen als Teil einer fruchtbaren Verbindung der Kultur- und Verfassungsgeschichte vollzogen. Dabei werden auch öffentliche politische Handlungen als regelhafte oder gar regelgeleitete Rituale gedeutet, mit denen in vormodernen Gesellschaften soziale Ordnung gestiftet oder bestätigt wurde. Die in dazu insbesondere an den Sonderforschungsbereichen 496 in Münster und 619 in Heidelberg entstandene Literatur kann hier in ihrer Breite nicht einmal annähernd aufgeführt werden. Vgl. dazu in Auswahl: Gerd Althoff: Die Macht der Rituale. Symbolik und Herrschaft im Mittelalter, Darmstadt, 2003; DERs. (Hg.): Formen und Funktionen öffentlicher Kommunikation im Mittelalter (Vorträge und Forschungen 51), Stuttgart, 2001; DERS.: Spielregeln der Politik im Mittelalter. Kommunikation in Frieden und Fehde, Darmstadt, 1997; Jürgen Martschukat und Steffen Patzold (Hrsg.): Geschichtswissenschaft und „performative turn“. Ritual, Inszenierung und Performanz vom Mittelalter bis zur Neuzeit (Norm und Struktur 19), Köln/ Weimar/Wien, 2003; FANK Rexrотн: «Rituale und Ritualismus in der historischen Mittelalterforschung. Eine Skizze», in: Mediävistik im 21. Jahrhundert. Stand und Perspektiven der internationalen und interdisziplinären Mittelalterforschung, hg. von Hans-Werner Goetz und Jörg Arnut, München, 2003, S. 391-406; Barbara Stollberg-Rillinger: Des Kaisers alte Kleider. Verfassungsgeschichte und Symbolsprache des Alten Reiches, München, 2008; DIES.: «Symbolische Kommunikation in der Vormoderne. Begriffe - Thesen - Forschungsperspektiven», in: Zeitschrift für historische Forschung 31 (2004), S. 489527. - Speziell zu den mittelalterlichen Herrschertreffen: Gerald Schwedler: Herrschertreffen des Spätmittelalters. Formen - Rituale - Wirkungen (Mittelalter-Forschungen 21), Ostfildern, 2008; DERS.: 
Gerade deshalb aber standen sie auch unter besonderer Beobachtung. Aufmerksam registrierten interessierte Zeitgenossen feinste Nuancen im Verhalten und Auftreten der beteiligten Fürsten oder Abweichungen von „Erwartbaren“ in deren öffentlichem Handeln. Im Rahmen des üblichen begrenzten und allgemein verständlichen Kanons von Gesten und Handlungen bei Ritualen besaßen die Akteure nämlich auch Möglichkeiten zur pragmatischen Differenzierung ihres Verhaltens. Auf diese Weise konnten sie mit Hilfe symbolischer Kommunikation eigene Ambitionen betonen oder die Qualität der gegenwärtigen und künftigen Beziehungen zum Gegenüber und anderen Beteiligten demonstrieren. ${ }^{13}$ Insofern lässt auch die Beobachtung, wer unter den Beteiligten maßgeblich die Gestaltung und den Ablauf der Rituale bestimmte, oder wer sich herausnehmen konnte, sie durch Provokation zu stören, durchaus wichtige Rückschlüsse auf das herrschende Kräfteverhältnis $\mathrm{zu}^{14}$

In der pragmatischen Differenzierung eigenen rituellen Verhaltens sowie des gesamten zeremoniellen Auftretens bei Herrschertreffen lagen für die einzelnen Fürsten also große kommunikative Möglichkeiten. Zugleich aber besaß es auch eine erhebliche Brisanz, denn Missverständnisse und Fehltritte, auch demonstrative Ablehnung, waren dabei keineswegs ausgeschlossen. Ein Ritual konnte falsch interpretiert werden, Repräsentation konnte schlichtweg scheitern und ihr Ziel verfehlen, wenn nicht gar schaden. Ein bekanntes und gut untersuchtes Beispiel dafür ist das Auftreten Karls des Kühnen von Burgund bei seinem Treffen mit Kaiser Friedrich III. und zahlreichen Reichsfürsten zu Trier 1473. ${ }^{15}$ Der Burgunderherzog begegnete dem Kaiser mit dem Ziel, ein eigenes

«Deutsch-französische Herrschertreffen im 14. Jahrhundert. Dynastische und staatliche Beziehungen im Wandel», in: Regnum et imperium. Die französisch-deutschen Beziehungen im 14. und 15. Jahrhundert, hg. von Stefan WeIss (Pariser Historische Studien 83), München 2008, S. 55-99; Ders.: «Politik und Ritual Herrschertreffen als Handlungsform politischer Praxis im Spätmittelalter», in: Jahrbuch der historischen Forschung in der Bundesrepublik Deutschland 2004 (2005), S. 53-59; DERS. / GerRIT JASPER SCHENK: «Herrschertreffen. Ritual, Zeremoniell und Politik bei spätmittelalterlichen repräsentativen Akten», in: Mitteilungen der Residenzenkommission 13/1 (2003), S. 35-43; GERRIT JASPER SCHENK: Zeremoniell und Politik. Herrschereinzüge im spätmittelalterlichen Reich (Forschungen zur Kaiser- und Papstgeschichte des Mittelalters. Beihefte zu J.F. Böhmer, Regesta imperii 21), Köln/Weimar/Wien, 2003; DERS.: «Friedrich III. in Besançon 1442 und in Metz 1473 oder: Von geglückten und gescheiterten Herrschertreffen mit dem Burgunderherzog», in: Außenpolitisches Handeln im ausgehenden Mittelalter. Akteure und Ziele, hg. von Sonja Dünnebeil und Christine Ottner (Forschungen zur Kaiser- und Papstgeschichte des Mittelalters. Beihefte zu J.F. Böhmer, Regesta Imperii 27), Wien/Köln/Weimar, 2007, S. 97-141; Peter JohaneK und Angelika Lampen (Hrsg.): Adventus. Studien zum herrscherlichen Einzug in die Stadt (Städteforschung 75), Köln/Weimar/Wien, 2009; Martin Kintzinger: «Der weiße Reiter. Formen internationaler Politik im Spätmittelalter», in: Frühmittelalterliche Studien 37 (2003), S. 315-353.

13. Gerd Althoff: «Die Veränderbarkeit von Ritualen im Mittelalter», in: Ders.: Formen und Funktionen, S. 157-176; SCHENK, Friedrich III., S. 100-103; SCHWEDLER, Herrschertreffen, S. 318-329.

14. Althoff, Veränderbarkeit, S. 171; Martin Kintzinger: «Panne oder Provokation. Gewollte Regelbrüche in Politik und Diplomatie des Spätmittelalters», in: Wertekonflikte - Deutungskonflikte, hg. von Barbara Stollberg-Rilinger und Thomas Weller (Symbolische Kommunikation und gesellschaftliche Wertesysteme, Schriftenreihe des SFB 496, 16), Münster, 2007, S. 85-104.

15. Schenk, Friedrich III.; Petra Ehm-Schnocks: «Der Tag von Trier 1473 und die Grenzen des Reiches. Karl der Kühne, Friedrich III. und die Kurfürsten», in: DünNEBEIL/OtTNER (Hrsg.): Außenpolitisches Handeln, S. 143-157; Dies.: “„... und begeret ein kunig zu werden“. Beobachtungen zu einem 
Königtum zu erlangen und seine Ambitionen auf einen späteren Aufstieg zum Deutschen König zu untermauern. Zu diesem Zweck bemühte sich Karl zwar um eine demonstrative Unterordnung unter den Kaiser. Allerdings wirkte sein prachtvolles Auftreten wie eine unzulässige Vorwegnahme der künftigen königlichen Würden. Das burgundische Hofzeremoniell, bei dessen Inszenierung die Person des Herzogs im Mittelpunkt stand, war im Reich nicht üblich und wirkte auf die deutschen Fürsten befremdlich. In der Folge verprellte Karl der Kühne mit seinen offen demonstrierten Ambitionen die Reichsfürsten und letztlich auch den Kaiser, was zur breiten Ablehnung seiner Königspläne führte.

Und Georg von Podiebrad? Er befand sich zu Beginn seiner Königsherrschaft in einer vergleichbaren Situation wie Karl der Kühne. Die persönlichen Begegnungen mit seinen Gegnern am Beginn seiner Königsherrschaft boten ihm eine ausgezeichnete Bühne, seine eigenen Ambitionen darzustellen und für sein Königtum Akzeptanz und Legitimation zu erlangen. Es wird also im Folgenden zu beobachten sein, wie sich Georg von Podiebrad den verschiedenen Fürsten gegenüber verhielt. Versuchte er zum Beispiel, durch prunkvolle Selbstdarstellung seinen Anspruch auf Führungsmacht zu untermauern? Oder war er um ein demonstrativ bescheidenes Entgegenkommen bemüht, um die Vorbehalte gegenüber seiner Person abzubauen? Auf der anderen Seite ist das Verhalten der Fürsten und Monarchen zu bewerten, die Georg von Podiebrad in aller Öffentlichkeit gegenübertraten. Das geschah jeweils zu einem Zeitpunkt, zu dem sie den adligen Aufsteiger noch nicht als König von Böhmen anerkannt hatten. Wie gingen sie mit dieser Situation um, in der sie vor einem politisch relevanten Publikum um eine sichtbare - und damit verbindliche - Stellungnahme nicht herumkamen? Bei alledem darf aber auch der Aspekt des gegenseitigen politischen Interesses nicht vergessen werden. Er zwang alle Beteiligten zu praktischen Lösungen und Kompromissen, durch die eine öffentliche Inszenierung des gegenseitigen Verhältnisses überhaupt erst ermöglicht wurde.

Diese Fragen sollen im Auge behalten werden, wenn ich im Folgenden einige Fallbeispiele vorstelle. Wie beschrieben, richtet sich das Hauptaugenmerk dabei vor allem auf die erstmaligen Begegnungen nach Podiebrads Königswahl. In diesen Situationen mussten die Aspekte von öffentlicher Wahrnehmung und Akzeptanz die größere Bedeutung gehabt haben als zu jedem anderen Zeitpunkt.

Herrschertreffen: Friedrich III. und Karl der Kühne in Trier 1473», in: Auswärtige Politik und internationale Beziehungen im Mittelalter (13. bis 16. Jahrhundert), hg. von DiETER BERG, Martin Kintzinger und Pierre Monnet (Europa in der Geschichte 6), Bochum, 2002, S. 233-257; Dies.: «„L'empereur ne droit pas être un non-Allemand“" Charles le Téméraire, Frédéric III et l'Empire», in: WeIss, Regnum et imperium, S. 235-248. 


\section{Vermeidung von Klarheit: DAs Treffen mit Kaiser Friedrich III. vor WIEN}

Das erste dieser Treffen, das zugleich von wegweisender Bedeutung war, fand zwischen Georg von Podiebrad und Kaiser Friedrich III. statt, und zwar vom 25. September bis zum 2. oder 3. Oktober 1458 an der Donau östlich von Wien. ${ }^{16}$ Bis dahin hatte der Kaiser eine Anerkennung der Wahl Podiebrads verweigert, er bemühte sich im Sommer 1458 sogar darum, eine weit reichende Koalition für einen Krieg gegen Böhmen zustande zu bringen. ${ }^{17}$ Dem trat Podiebrad im August dieses Jahres mit Waffengewalt entgegen. Bereits seit dem Frühjahr befanden sich böhmische Truppen in Österreich, wo sie in den Erbfolgestreit nach dem Tod von König Ladislaus eingegriffen hatten. Nun aber erschien dort Podiebrad selbst an der Spitze eines Heeres von angeblich über 30.000 Mann und drängte die zwischenzeitlich miteinander versöhnten Habsburger in die Defensive. Aus dieser Situation heraus kam es zur ersten Kontaktaufnahme zwischen Podiebrad und Gesandten des Kaisers, bei der man sich auf ein persönliches Treffen der Herrscher am 16. September zwischen Kreuzenstein und Korneuburg einigte. Überraschenderweise ließ Kaiser Friedrich diesen Termin jedoch verstreichen. Als das böhmische Heer darauf mit neuen Gewalttaten antwortete, fand man jedoch rasch einen neuen Termin für eine Begegnung am 25. September bei Wien. ${ }^{18}$

Die Gründe für diese Verschiebung sind nicht eindeutig zu bestimmen. Vielleicht hoffte der Kaiser auf eine Veränderung der Situation - immerhin war ein so großes Heer wie das böhmische nicht ohne logistische Probleme dauerhaft im Feld zu halten. Vielleicht kann man sein Abwarten auch als betonte Inszenierung der Distanz deuten, die er zunächst noch zwischen sich und demjenigen sah, „der sich König in Böhmen nennt“, wie die Habsburger Podiebrad bezeichneten. ${ }^{19}$ Schließlich musste der Kaiser sich bewusst gewesen sein, dass ein persönliches Zusammentreffen mit dem neuen böhmischen König angesichts der militärischen Lage nur auf dessen faktische Anerkennung hinauslaufen konnte. Möglich wäre in dieser Hinsicht aber auch, dass der Kaiser nicht mit dem durch seine Räte sicher vereinbarten Ablaufplan seiner ersten

16. Beide Protagonisten sind sich 1442 erstmals persönlich begegnet, als der junge Adelige Georg von Podiebrad als Mitglied einer böhmischen Gesandtschaft an den Hof Friedrichs III. kam. Siehe dazu HLAVÁČEK, Beziehungen, S. 290 f., der ansonsten jedoch das Herrschertreffen von 1458 ignoriert und stattdessen fälschlich die Begegnung Friedrichs und Georgs 1459 in Brünn (Brno) als erstes persönliches Zusammentreffen nach der Krönung des böhmischen Königs darstellt (ebenda, S. 293). Zu den Ereignissen in Österreich im Sommer/Herbst 1458 sowie zum darauf folgenden Treffen zwischen Friedrich III. und Georg von Podiebrad siehe Niederstätter, 1400-1522, S. 250-255; Čornej/Bartlová, Velké dějiny, S. 163 f.; UrbáneK, Věk poděbradský, Bd. 3, S. 384-394 und S. 424-436; BACHMANN, Jahr, S. 149 f. und S. 156-172.

17. BACHMANN, Jahr, S. $161 \mathrm{f}$.

18. Anonymi Rerum Austriacarum historia (1454-1467), hg. von Adrian Rauch, Wien, 1794, S. 35 f.; Thomas Ebendorfer, Chronica Austriae, hg. von Alphons Lhotsky (Monumenta Germaniae Historica. Scriptores rerum Germanicarum, NS 13), Berlin/Zürich, 1967, S. 454-457.

19. So Herzog Albrecht VI. von Österreich in einem Schreiben an den Schlesischen Bund (1458, Juni 10): Girsik, der sich konig in Behem nennet. Siehe PALACKÝ, Urkundliche Beiträge, Nr. 160. 
persönlichen Begegnung mit dem von ihm nicht anerkannten böhmischen König zufrieden war. Das war ein äußerst heikler Punkt, weil das übliche Begrüßungsritual den Rang der Beteiligten und ihr gegenseitiges Verhältnis unmittelbar sichtbar machte, in dieser Hinsicht also von vornherein Klarheit verlangte. Bevor der Kaiser dem böhmischen Aufsteiger auf öffentlicher Bühne gegenübertreten konnte, musste also unbedingt geregelt sein, wie sich beide im Rahmen des Begrüßungszeremoniells zueinander verhalten sollten, um spätere Entscheidungen nicht zu präjudizieren.

Die wichtigsten Quellen für das nun folgende Treffen sind von österreichischer Seite die anonym verfasste „Rerum Austriacarum historia“20 und von böhmischer Seite der Bericht des Jobst von Einsiedel, eines Sekretärs und engen Vertrauten König Georgs, an seine Heimatstadt Eger. ${ }^{21}$ Beide Quellen stimmen darin überein, dass das Treffen der Herrscher bei den drei Donaubrücken östlich von Wien in freundlicher Atmosphäre verlief. Der gewählte Ort eignete sich in besonderem Maße für die Inszenierung eines Herrschertreffens. Flüsse hatten eine hohe symbolische Bedeutung als Grenzen. Brücken konnten der neutrale Ort zwischen diesen Grenzen sein oder der symbolische Weg für deren Überwindung. ${ }^{22}$ Am Westufer der Donau, auf Höhe der mittleren Brücke, hatte der Kaiser zwei Zelte aufschlagen lassen, die als Verhandlungs- und Beratungsräume zu nutzen waren. Podiebrad, der sich am Ostufer von Norden her näherte, wurde zuerst am 25. September und dann noch einmal am folgenden Tag an der nördlichen Brücke von einer kaiserlichen Delegation empfangen. An beiden Tagen geleiteten ihn zwei Ritter, indem sie ihn am Arm führten, über die mittlere Brücke zum Kaiser. Am westlichen Flussufer, vor den zwei Zelten, erwartete ihn Friedrich; Podiebrad kniete vor ihm nieder und - so der anonyme Chronist - erbot sich ihm demütig, das heißt, er zeigte durch Gestik und Worte öffentlich seine Unterwerfung und bot dem Kaiser seine Dienste an. Dieser hob ihn auf, umarmte ihn und führte ihn in eines der Zelte. ${ }^{23}$

Mehr ist aus den Berichten nicht über den Ablauf der Begegnung zwischen den Herrschern zu erfahren. Ansonsten sind nur die Ergebnisse der insgesamt

20. Anonymi Rerum Austriacarum historia, S. 36 f.

21. «Jobst von Einsiedel und seine Correspondenz mit der Stadt Eger», hg. von Franz KürSCHNER, in: Archiv für österreichische Geschichte, Bd. 39, Wien 1868, S. 245-292, hier S. 267-269, Nr. IX.

22. Reinhard SCHNEIdER: «Mittelalterliche Verträge auf Brücken und Flüssen (und zur Problematik von Grenzgewässern)», in: Aus Geschichte und ihren Hilfswissenschaften. Festschrift für Walter Heinemeyer zum 65. Geburtstag, hg. v. Hermann Bannasch und Hans-Peter Lachmann, Marburg, $1979=$ Archiv für Diplomatik 23 (1977), S. 1-24. Vgl. auch SCHENK, Friedrich III., S. 121.

23. Anonymi Rerum Austriacarum historia, S. 36: Des obgenanten Iars am Montag vnd Eritag vor sannd Michels tag köm der Erwellt kunig Pehem zw der aussern Tunaw pruck. Zw dem fuegt sich der Römisch kaiser vntz zw der Mittern pruck, do hett man auffemacht Zwai getzellt. Vnd tett darnach pottschafft dem Erwellten von Pehem, den weissten zwen Ritter vnder den armen über die pruck. Vnd als er nehent gegen dem Römischen kaiser, do khniett er nyder vnnd erpatt sich diemutiklich gegen dem kaiser. Der kaiser in auftzach vnd fürt in under das getzellt, daselbs sy vnd ir paider Rett miteinander taidingten. Auch Jobst von Einsiedel, S. 268, berichtete an die Stadt Eger, dass die Herrscher an zwei Tagen (zcweien malen) freundlich miteinander verhandelten. 
einwöchigen Unterhandlungen bekannt. ${ }^{24}$ Deutlich geworden ist aber die Betonung des faktischen Ranges der Beteiligten sowie das gegenseitige Bemühen um respektvollen Umgang miteinander. Man begegnete sich nicht auf der Brücke über dem Fluss, wofür beide Seiten aufeinander hätten zugehen müssen. Auch verzichtete Podiebrad darauf, seine militärische Überlegenheit für eine Demonstration eigener Machtansprüche auszunutzen. Stattdessen erwies der böhmische König dem Kaiser alle seinem Rang gebührende Ehre. In aller Demut, wie ein Bittsteller, überquerte er in Gänze die Donaubrücke, um vor dem ihn erwartenden Kaiser auf die Knie zu fallen. Dann suchte er um die Belehnung mit Böhmen an, wobei er offenbar jeglichen fordernden Nachdruck vermied. Ohne Rücksicht auf das tatsächliche Kräfteverhältnis, mit dem Podiebrad die persönliche Zusammenkunft mit dem Kaiser erzwungen hatte, überließ er diesem nun gänzlich die seinem Rang zukommende Entscheidung über die faktische Legitimation des neuen böhmischen Königs.

Friedrich seinerseits behandelte Podiebrad mit freundlichem Entgegenkommen - er ließ ihn durch ein Ehrengeleit zu sich führen, hob den Knienden auf und umarmte ihn. Er signalisierte ihm damit nahezu eine Akzeptanz seines böhmischen Königtums, ohne ihn jedoch nahezu endgültig anzuerkennen. Jobst von Einsiedel beschrieb in seinem Brief an die Stadt Eger das weiterhin in der Unklarheit schwebende, komplizierte Verhältnis so, dass man sich darauf geeinigt hätte, „dass sich der Kaiser zum König halte wie ein Römischer Kaiser sich zu einem böhmischen König und Kurfürsten des Reiches halten soll“.25

Allerdings berichtete Einsiedel darüber hinaus, dem König sei die vom Kaiser erbetene Belehnung mit den böhmischen Regalien bereits fest in Aussicht gestellt worden. Offenbar schrieb der böhmische Beobachter dies entweder unter dem frischen Eindruck der freundlichen Atmosphäre, die zwischen Kaiser und König geherrscht hatte, oder er bezog sich auf tatsächliche mündliche Abmachungen. Der ansonsten gut informierte anonyme Verfasser der „Rerum Austriacarum historia“ wusste hingegen nur von "weiteren Wünschen“" Podiebrads, die ihm Friedrich III. aber nicht erfüllte. ${ }^{26}$ Dementsprechend betonte das einzige schriftliche Dokument, das aus dem Herrschertreffen hervorging, weiterhin die vorsichtige Distanz zwischen dem Kaiser und dem Aufsteiger. In dem zwischen beiden Seiten geschlossenen Vertrag über die Beilegung ihrer Streitigkeiten wurde Podiebrad weiterhin nicht als König von Böhmen bezeichnet, noch wurde seine förmliche Anerkennung und Belehnung angekündigt. Offiziell war er lediglich „Herr Jörg, der von den Herren, Rittern und Knechten, von Städten und der Landschaft des Königreichs zu Böhmen

24. «Vertragsurkunde vom 3. Oktober 1458» in: Materialien zur österreichischen Geschichte, hg. von Joseph ChMEL, Bd. 2, Wien, 1838, Nr. 130, S. 161-163.

25. Jobst von Einsiedel, S. 268: (...), also das sich der keiser zcu mein hern dem konig helt als ein romischer keiser sich zcu eyn pehmischen konig vnd öbersten kurfürsten halten sol (...).

26. Anonymi Rerum Austriacarum historia, S. 36. 
erwählt und gekrönt ist“. ${ }^{27}$ Und auch in der kaiserlichen Kanzlei sowie in der österreichischen Öffentlichkeit blieb Podiebrad nur derjenige, „der sich König zu Böhmen nennt" bzw. „der erwählte König von Böhmen“. ${ }^{28}$

Offenbar hatte sich Friedrich III. gegenüber dem böhmischen Aufsteiger politischen Handlungsspielraum gewahrt, den er schließlich zu nutzen verstand. Im Juni 1459 erklärte sich Georg von Podiebrad bereit, den Kaiser gegen seinen gefährlichsten Rivalen in Ostmitteleuropa, den ungarischen König Matthias Corvinus, zu unterstützen. Erst für diese Abkehr von seinem bisherigen Verbündeten und Schwiegersohn Matthias erlangte der böhmische König nun endlich die vollständige Anerkennung durch den Kaiser. Am 31. Juli 1459, zehn Monate nach dem nach dem Treffen an den Wiener Donaubrücken, belehnte Friedrich III. Georg von Podiebrad mit den Regalien des Königreichs Böhmen. ${ }^{29}$

\section{Das MeisterstüCK des neuen Königs: Der Fürstentag zu Eger 1459}

Vor der förmlichen Belehnung durch den Kaiser hatte Georg von Podiebrad ein weiteres persönliches Treffen mit Gegnern und Thronrivalen zu bestehen, das für seinen weiteren Erfolg wegweisend werden sollte. Im April 1459 kam es in Eger (Cheb) zu mehrwöchigen Verhandlungen zwischen dem böhmischen König und den wichtigsten Vertretern der deutschen Fürstenhäuser der Wittelsbacher, Hohenzollern und Wettiner. ${ }^{30}$ Dabei sollte es vor allem um die Beilegung des sächsisch-böhmischen Konflikts gehen, der sich seit einigen Jahren aus komplexen Streitigkeiten zu einem unerklärten Grenzkrieg ausgeweitet hatte. Die Wettiner als Herzöge von Sachsen und Landgrafen von Thüringen waren aber auch die schärfsten Gegner des Königtums Podiebrads, allen voran der wettinische Thronkandidat Herzog Wilhelm III. von Sachsen. An ihrer Seite standen als enge Verbündete und Verwandte die Markgrafen von Brandenburg und Burggrafen von Nürnberg aus dem Haus Hohenzollern,

27. Chmel, Materialien, Nr. 130, S. 162: (...) der bemelt her Jorg, der von den vonn herrn, rittern vnd knechten, den vonn stetn vnd der lanndtschafft zu kuni erwellt vnd gekront ist (...).

28. Dies wird belegt durch die Überschrift des Eintrags der Vertragsurkunde vom 2. Oktober 1458 in das kaiserliche Kanzleiregister: Die Bericht, so der kaiser mit dem Jorsigkn der sich nennt kunig zu Behem ze Wienn vor den prukken beslossn hat (CHMeL, Materialien, Nr. 130, S. 161) und durch die entsprechende Bezeichnung Podiebrads (der erwellt kunig von pehem bzw. qui se regem Bohemie titulat) in den zeitgenössischen österreichischen Chroniken: Anonymi Rerum Austriacarum historia, S. 36 f.; ThомAS EBendorfer, Chronica Austriae, S. 454.

29. Čornej / Bartlová, Velké dějiny, S. 171-173; HlaváČEK, Beziehungen, S. 293; Heymann, George of Bohemia, S. 202-212; URBÁNEK, Věk poděbradský, Bd. 3, S. 536-546; KARL NeHring: Matthias Corvinus, Kaiser Friedrich III. und das Reich. Zum hunyadisch-habsburgischen Gegensatz im Donauraum, München, 1989, S. 15-17; Adolf Bachmann: Böhmen und seine Nachbarländer unter Georg von Podiebrad 14581461 und des Königs Bewerbung um die deutsche Krone, Prag, 1878, S. 88-110.

30. Zu den Hintergründen, Ereignissen und Folgen der Egerer Fürstentage im April und November 1459 siehe jetzt den Sammelband Thieme/Tresp (Hrsg.), Eger 1459. Darin zu den Interessen der Wittelsbacher, SCHWARz, Wittelsbacher; zur Politik der Hohenzollern, Müller, Kärrnerarbeit; zu den Streitigkeiten der Wettiner mit Böhmen Tresp, Fürstentreffen. 
deren wichtigster Vertreter der in den fränkischen Herrschaften regierende Markgraf Albrecht Achilles von Brandenburg war. Hingegen waren die Wittelsbacher, allen voran Kurfürst Friedrich von der Pfalz, von vornherein zur Anerkennung des neuen böhmischen Königs bereit, um diesen als Verbündeten für ihre Reichspolitik zu gewinnen. Allerdings waren auch ihre Beziehungen zur Böhmischen Krone nicht ungetrübt. Schon seit längerem lag eine wichtige Linie der Wittelsbacher, die Herzöge von Bayern-Landshut, mit Böhmen im Streit um einige Herrschaften in Bayern.

Die Initiative zum Egerer Fürstentag ging offenbar vom brandenburgischen Markgrafen Albrecht Achilles aus, der eine Koalition der Wittelsbacher mit dem böhmischen König verhindern wollte. Statt dessen versuchte er eine Aussöhnung zwischen Georg von Podiebrad und den Wettinern zu vermitteln, die nach Möglichkeit in ein Bündnis von Brandenburgern und Sachsen mit Böhmen gegen die Wittelsbacher münden sollte. Im Februar 1459 organisierte der Markgraf ein Treffen der Räte im oberfränkischen Wunsiedel, bei dem eine Einigung zwischen Böhmen und Sachsen in wesentlichen Punkten vorbereitet wurde. Dabei beschloss man ein Treffen der Wettiner mit dem böhmischen Herrscher, wobei Albrecht Achilles den „Teidingsmann“, den Vermittler, spielen sollte. ${ }^{31}$ Hier ist auch noch einmal daran zu erinnern, dass Podiebrad bis dahin - trotz der vagen Zusage von Anfang Oktober 1458 - noch immer keine offizielle Anerkennung vom Kaiser erhalten hatte. Die Legitimation seines Königtums war also weiterhin unklar. Folglich konnte man ihn von Seiten der deutschen Fürsten immer noch als „Aufgerückten“ (uffgeruckten) bezeichnen oder ihn als lediglich "Gewählten“ (eynen erwelten) abqualifizieren. ${ }^{32}$

Vom Egerer Fürstentag sind vor allem die zahlreichen Verträge, Heiratsverabredungen und einige Verhandlungsunterlagen überliefert. ${ }^{33}$ Ergänzend können weitere Informationen aus den Egerer Stadtrechnungen hinzugezogen werden. ${ }^{34}$ Über den zeremoniellen Ablauf und das gegenseitige Verhalten der beteiligten Fürsten informieren verschiedene Berichte beteiligter Beobachter. Sie erfassen zwar nur die ersten Tage des Fürstentreffens, lassen aber immerhin einige interessante Details erkennen. Besonders ausführlich sind die Briefe der Gesandten Herzog Ludwig IX. von Bayern-Landshut an ihren Herrn. Im ersten Schreiben vom 11. April 1459 wird der Auftakt des Treffens, die Ankunft und erste Begegnung der Fürsten beschrieben. ${ }^{35}$ Ein

31. Über die Vermittlungstätigkeit Markgraf Albrechts ausführlich MüLLER, Kärrnerarbeit, S. 178-192.

32. Siehe dazu auch oben Anm. 6. Die Zitate aus Tresp, Fürstentreffen, Editionsanhang, Nr. 2.

33. Die meisten davon sind jetzt neu ediert in den Editionsanhängen der Aufsätze von MüLLER, Kärrnerarbeit, S. 211-226 und TRESP, Fürstentreffen, S. 110-128. Siehe auch die Übersicht ebenda, S. 72 f.

34. Hana Knetlová: «Die Stadt Eger als Bühne für Fürstentreffen und Hochzeiten um 1459», in: Thieme/Tresp (Hrsg.), Eger 1459, S. 329-335; Karl Siegl: «Zur Geschichte der Fürstentage Georgs von Podiebrad in Eger in den Jahren 1459, 1461 und 1467», in: Mitteilungen des Vereins für Geschichte der Deutschen in Böhmen 42 (1904), S. 203-226; DerS.: «Geschichte der Vermählung Albrechts des Beherzten von Sachsen mit Sidonia von Böhmen zu Eger im Jahre 1459», in: Egerer Jahrbuch 40 (1910), S. 91-111.

35. Urkunden und Beilagen zum Kampfe der wittelsbachischen und brandenburgischen Politik in den Jahren 1459 bis 1465 (Urkunden und Beilagen zur Geschichte Herzogs Albrecht IV. von Bayern und seiner Zeit I/1), hg. von Gustav Freiherr von Hasselholdt-Stockheim, Leipzig, 1865, Nr. IXa-c. 
zweites undatiertes Schreiben der bayerischen Räte schildert die Inhalte der pfälzisch-böhmischen Verhandlungen. ${ }^{36}$ Ebenfalls am 11. April 1459 sandten die Räte Herzog Wilhelms von Sachsen zwei Berichte an ihren Herrn, der auf der nahe gelegenen oberfränkischen Burg Thierstein den Fortschritt der Verhandlungen abwartete. ${ }^{37}$ Während der kurze erste Bericht wichtige Ergänzungen über den Empfang des pfälzischen Kurfürsten durch Georg von Podiebrad in Eger bietet, gibt der zweite einen detailreichen Einblick in die Gespräche zwischen König Georg und Markgraf Albrecht. Leider brechen diese ergiebigen Quellen schon nach den ersten Tagen ab. Über den weiteren Ablauf des Fürstentreffens stehen daher keine vergleichbaren Informationen mehr zur Verfügung. Lediglich den Zeitpunkt, als am 19./20. April die Verhandlungen erfolgreich abgeschlossen wurden und man die Wettiner zur Besiegelung der vereinbarten Verträge nach Eger einlud, beleuchten noch einmal zwei Briefe Herzog Wilhelms an seinen Bruder Kurfürst Friedrich II. von Sachsen, die wiederum interessante Details enthalten. ${ }^{38}$

Aus allen diesen Quellen wird deutlich, dass die Choreographie auf der öffentlichen Bühne in Eger eindeutig in den Händen des Gastgebers, des böhmischen Königs Georg von Podiebrad lag. ${ }^{39}$ Und dieser nutzte seine Rolle mit großem Geschick vor allem zur Durchsetzung seiner vordringlichen Interessen: der endgültigen Anerkennung seines umstrittenen Königtums und festen Einbindung seiner Familie in das dynastische Geflecht der deutschen Fürstenhäuser. Für Podiebrad kam es vor allem darauf an, die um ein Bündnis mit ihm rivalisierenden Reichsfürsten geschickt gegeneinander auszuspielen, um daraus den größtmöglichen Gewinn für Böhmen, für sein Königtum und für seine eigene Dynastie zu erzielen. Geeignete Gelegenheiten dafür boten sich ihm von Anfang an. Vor allem den ersten persönlichen Begegnungen der Fürsten kam eine wegweisende Rolle als Stimmungsbarometer zu. Das dabei übliche Zeremoniell umfasste eine ganze Reihe von Ritualen wie Begrüßung, Ehrenbezeugung oder Einholung, deren virtuose Ausgestaltung einen gewissen Raum für anspielungsreiche symbolische Kommunikation bot. ${ }^{40}$ Das galt nicht nur für den Gastgeber selbst, sondern auch für den Empfangenen, der hier auch die Möglichkeit eigener repräsentativer Selbstdarstellung erhielt - jedenfalls soviel, wie ihm durch den Gastgeber als Zeichen guten Einvernehmens gewährt wurde.

Unter Berücksichtigung dieser Voraussetzungen lassen sich die Ereignisse der ersten Tage aus den Berichten der bayerischen und sächsischen Beobachter

36. Regesten zur Geschichte Friedrichs des Siegreichen, Kurfürsten von der Pfalz, hg. von KARL MENZEL, München, 1862 (Quellen und Erörterungen zur bayerischen und deutschen Geschichte 2), S. 306-308.

37. Tresp, Fürstentreffen, Beilagen Nr. 1 und 2.

38. Tresp, Fürstentreffen, Beilagen Nr. 3 und 4.

39. Dazu besonders Tresp, Fürstentreffen, S. 100-104.

40. Siehe dazu: SCHwedler, Herrschertreffen, S. 341-350; SCHEnK, Zeremoniell und Politik; DERS. Friedrich III. Vgl. auch: Аснім Тномаs Наск: «Das Empfangszeremoniell bei mittelalterlichen PapstKaiser-Treffen» (Forschungen zur Kaiser- und Papstgeschichte des Mittelalters. Beihefte zu J.F. Böhmer, Regesta imperii 18), Köln/Weimar/Wien, 1999. 
wie folgt rekonstruieren: Am 7. April 1459 hielt König Georg feierlichen Einzug in seine Stadt Eger, ${ }^{41}$ begleitet von 900 prächtig gerüsteten Reitern und 100 Wagen. Am folgenden Tag, dem 8. April, kam der eigentliche Vermittler des Fürstentreffens, Markgraf Albrecht von Brandenburg, vor Eger an. Zu seiner Begrüßung ritt Podiebrad vor die Stadt. Sobald ihn der Markgraf erblickte, stieg er von seinem Pferd und ging zu Fuß auf den König zu. Im Grunde lag darin schon die Inszenierung eines deutlichen Rangunterschiedes - ein erstes Anzeichen der Bereitschaft zur Anerkennung des Aufsteigers als neuen Herrscher Böhmens durch den Markgrafen. Der König reagierte darauf anscheinend relativ kühl. Er habe das entgegenkommende Verhalten Markgraf Albrechts lediglich "geduldet", notierten die bayerischen Gesandten. Vermutlich meinten sie damit, dass dieser Empfang nicht über ein Mindestmaß der üblichen öffentlichen Begrüßungsgesten, die vom Gastgeber erwartet werden mussten, hinauskam.

Umfassender als vom ersten Aufeinandertreffen zwischen dem böhmischen König und dem brandenburgischen Markgrafen berichteten die Beobachter beider Seiten dann über den Empfang des Kurfürsten Friedrich von der Pfalz. Als das Nahen des Wittelsbachers in Eger bekannt wurde, sandte ihm König Georg eine Delegation von 80 Reitern unter der Führung hochrangiger böhmischer Adeliger entgegen. Diese sollte ihn eine halbe Meile vor Eger aufhalten, bis der König selbst zu ihm käme. Allerdings wollte der Pfälzer darauf nicht eingehen und setzte seinen Weg fort. Daher kam Podiebrad nun selbst heraus und ritt ihm eine Viertelmeile vor die Stadt entgegen. Die folgende erste Begegnung der beiden Fürsten gestaltete sich dann völlig anders als das Treffen Podiebrads am Tag zuvor mit Markgraf Albrecht von Brandenburg. Als der König dem Pfälzer Kurfürsten die Hand reichen wollte, machte dieser Anstalten vom Pferd zu steigen, um dem böhmischen König damit sogleich die Anerkennung seines übergeordneten Ranges zu signalisieren. Daran wurde er jedoch auf Befehl Podiebrads durch zwei böhmische Adelige gehindert, so dass sich die Fürsten, beide zu Pferd und somit auf Augenhöhe, die Hand zur Begrüßung reichten und sich dann mit besonders zuvorkommenden Worten gegenseitig Ehre und Respekt erwiesen. Nebeneinander reitend, wurden der König und der Kurfürst danach Zeugen eines ritterlichen Schaukampfes, der vor der Stadt durchgeführt wurde.

Anschließend ritt der wohlgeordnete Festzug der Fürsten in die Stadt Eger ein, wobei besonders der prächtige Auftritt der Pfälzer Aufsehen erregte. Dem Bericht der sächsischen Räte nach führte Kurfürst Friedrich ungefähr 300 Reiter an, die alle einheitlich ganz in Rot gekleidet waren. Friedrich selbst war außerordentlich stolz auf dieses Erscheinungsbild und äußerte sich sogar ganz unbescheiden, man hätte nie zuvor mehr Leute in einer Farbe gekleidet gesehen (man hett nye mehr lute in eyner farbe gesehen). Mit diesem Gefolge

41. Die alte Reichsstadt Eger befand sich seit 1322 als Reichspfand fest in der Hand der böhmischen Krone. 
zog er betont langsam und in lang gestreckter Kolonne in die Stadt ein. Dabei ritten nicht mehr als zwei oder drei Reiter nebeneinander, um den ganzen Zug noch größer erscheinen zu lassen, als er tatsächlich war.

Damit aber waren die öffentlich demonstrierten Freundlichkeiten zwischen dem böhmischen König und dem Pfälzer Kurfürsten noch nicht beendet. Als der Festzug auf dem großen Marktplatz von Eger angekommen war, wollte der Kurfürst dem König seine Dienstbarkeit beweisen, indem er ihn ehrenvoll bis zu seinem Quartier geleitete. Wiederum jedoch lehnte Georg es demonstrativ $\mathrm{ab}$, den von Friedrich akzeptierten Rangunterschied derart öffentlich zu inszenieren. Also zog das kurfürstliche Gefolge zunächst bis zur Unterkunft Friedrichs, wo dieser vermutlich einkehrte, und dann in voller Ordnung weiter rings um den großen Egerer Marktplatz zur Herberge des Königs im Haus der Egerer Patrizierfamilie Juncker. Zufrieden vermerkten die bayerischen Räte, dass dem König, den böhmischen Herren und vielen weiteren Augenzeugen dieser Auftritt sehr gefallen hätte. Und auch die sächsischen Beobachter berichteten, dass das prachtvolle Schauspiel anschließend in aller Munde war. Allerdings bemerkten sie auch, dass der ganze Einzug so spät beendet war, dass man das anschließende Abendessen (unplanmäßig?) bei Kerzenschein abhalten musste.

Als Zwischenfazit lässt sich also festhalten, dass das erste Zusammentreffen Podiebrads mit Markgraf Albrecht von Brandenburg auf die notwendigsten Formalien beschränkt blieb und somit das angespannte Verhältnis zwischen beiden Fürsten unterstrich. Hingegen wurde der Empfang Kurfürst Friedrichs von der Pfalz zur prachtvollen Inszenierung des gegenseitigen Einverständnisses genutzt, wobei insbesondere der Gast auf öffentlicher Bühne glänzen durfte. Dieser augenfällige Unterschied im Verhalten Podiebrads bei der Begrüßung einmal des Markgrafen und dann des Pfalzgrafen lässt sich unterschiedlich deuten. Er könnte der wittelsbachischen Perspektive der Beobachter entsprungen sein, die jedes Anzeichen für ein eventuell gestörtes Verhältnis der Böhmen zu den Hohenzollern und Wettinern bereitwillig aufnahmen. Er könnte aber auch einem durch Podiebrad demonstrierten Rangunterschied der Fürsten entspringen, indem er die Demutsbezeugung des Markgrafen seinem geringeren Rang entsprechend entgegennahm und diejenigen des Kurfürsten, der dem böhmischen König im Rang zwar nicht gleich-, aber doch nahekam, freundlich zurückwies. Noch wahrscheinlicher ist aber, dass dieses differenzierende Verhalten Podiebrads ein wichtiger Bestandteil seiner Verhandlungsstrategie mit den deutschen Fürsten war. Er kannte seine Position zwischen den rivalisierenden Parteien im Reich genau und nutzte diese klug für seine Inszenierung von Nähe und Distanz sowie zur Erweiterung des zeremoniellen Spielraums, der ihm darüber hinaus durch seine Rolle als Gastgeber sowie als faktisch ranghöchster Teilnehmer des Fürstentreffens zukam. Auf diese Weise konnte er die konkurrierend um seine Gunst buhlenden Fürsten für seine eigenen Ziele gegeneinander instrumentalisieren. Die kalkulierte öffentliche Bevorzugung Kurfürst Friedrichs von der Pfalz erhöhte 
dessen Bereitschaft zur vorbehaltlosen Anerkennung des neuen Königs, was gleichzeitig seinen wichtigsten Rivalen, Markgraf Albrecht von Brandenburg, unter Druck setzte. Noch hatten die Wettiner, deren Interessen der Markgraf trotz seiner Vermittlerrolle vertrat, weder auf ihre Ansprüche auf den böhmischen Thron verzichtet, noch hatten sie Podiebrad als König anerkannt. Wenn Albrecht Achilles sich nun aber der Situation beugte, dem Beispiel des Pfälzers folgte und Podiebrad anerkannte, konnte dies die sächsischen Herzöge, seine engsten Verbündeten, verprellen. Außerdem hätte der Markgraf damit auch seinen wichtigsten Trumpf für weitere Verhandlungen aus der Hand gegeben, denn noch war der König vor allem daran interessiert, Wettiner und Hohenzollern gutwillig zur Anerkennung zu bewegen.

Im Grunde aber war auch für den Markgrafen die verbale öffentliche Bekundung der Rangerhöhung des böhmischen Aufsteigers nur noch eine Frage des richtigen Zeitpunktes. Rituell hatte er den Rangunterschied bereits in seiner demütigen Begrüßung des böhmischen Königs demonstriert. Darüber hinaus wird man davon ausgehen müssen, dass Albrecht sich beim Begrüßungsritual nicht spontan so verhalten, sondern eine vorher zwischen brandenburgischen und böhmischen Räten getroffene Vereinbarung befolgt hatte. Ähnlich wie das für die Vorbereitung des Treffens zwischen Kaiser Friedrich III. und Podiebrad Ende September 1458 bei Wien zu vermuten ist, musste auch bei den böhmisch-brandenburgischen zu Wunsiedel im Februar 1459 die Frage des gegenseitigen Verhaltens der Fürsten bei der ersten Begegnungbehandelt worden sein. König Georg wäre wohlohne die Gewissheit, dass Markgraf Albrecht sich ihm durch öffentliche Gesten unterordnen würde, niemals zu seinem Empfang mit großem Gefolge vor die Stadt gekommen. In dieser öffentlichen Situation konnte er jedenfalls keine Zweideutigkeit dulden. Ebenso hätte sich der Markgraf, der Podiebrad offiziell noch nicht als König anerkannt hatte, wohl kaum zu einer Demutsgeste gegenüber dem zum Fürsten aufgestiegenen Adligen im Rahmen des Begrüßungsrituals herbeigelassen, wenn dies nicht schon von vornherein so vereinbart gewesen wäre - vielleicht war eine solche Verhaltenszusage des Markgrafen für die Böhmen sogar eine der Bedingungen für das Zustandekommen des Fürstentreffens gewesen.

Es ist also anzunehmen, dass die Begrüßungsszenen vor der Stadt Eger zumindest in ihren wichtigsten Teilen - inszeniert waren und einem vorher ausgehandelten Ablauf- und Verhaltensplan folgten. Das gilt selbstverständlich auch für das breit ausgestaltete Begrüßungsritual zwischen Podiebrad und dem Pfälzer Kurfürsten. Fraglich bleibt aber, inwieweit solche Inszenierungen auch die weiteren Verhandlungen prägten. Trotz lückenhafter Überlieferung lässt sich immerhin beobachten, wie Georg von Podiebrad in den ersten Tagen im geschickten Zusammenspiel mit Kurfürst Friedrich von der Pfalz den Markgrafen von Brandenburg unter Druck setzte.

Am 10. April kam es zur ersten persönlichen Unterhandlung zwischen dem böhmischen König und dem Markgrafen. Dabei brachte Podiebrad das Thema seiner mangelnden Anerkennung zur Sprache und klagte die Wettiner und 
- namentlich - auch den Markgrafen von Brandenburg an, ihm öffentlich in beleidigender Weise die königliche Legitimation abzusprechen. Die Rede des Königs gipfelte in einem zornigen Ausbruch gegen Markgraf Albrecht, indem er ihn direkt der Untreue gegenüber der Böhmischen Krone bezichtigte, deren Lehnsmann er war. ${ }^{42}$ Dabei attackierte Georg den überraschten Markgrafen in herausfordernder persönlicher Ansprache und sorgte so für einen kleinen Eklat. ${ }^{43}$ Als Absage an weitere Gespräche war dies freilich nicht zu verstehen. Dafür fehlte dem - lediglich in vertraulichen Berichten der sächsischen Räte überlieferten - verbalen Angriff Podiebrads die Öffentlichkeit. Aber der böhmische König hatte auf diese Weise dem Markgrafen, dem eigentlichen Initiator und Moderator des Egerer Fürstentreffens, jeglichen diplomatischen Spielraum genommen.

Als Albrecht Achilles sich am folgenden Tag wieder in das Quartier des Königs begab, um die bislang so ungünstig verlaufenen Verhandlungen wieder aufzunehmen, wurde er von einer eindrucksvollen Demonstration pfälzischböhmischer Eintracht überrascht. Gleichzeitig mit dem Markgrafen erschien dort auch sein Rivale, der Pfälzer Kurfürst, der umgehend am wartenden Brandenburger vorbei zu Georg von Podiebrad vorgelassen wurde. Lautstark verkündete dann der pfälzische Rat Johannes Lysura, dass sein Herr gekommen sei, um Podiebrad als König von Böhmen anzuerkennen und ein Bündnis mit ihm zu schließen. ${ }^{44}$ Nachdem er dieses Ansinnen feierlich begrüßt hatte, verabschiedete der König den Pfälzer Kurfürsten wieder und begab sich umgehend zu Markgraf Albrecht, der dem Geschehen in einem Nebenzimmer gelauscht hatte. Hier schilderte der König dem Markgrafen noch einmal das Verhalten des Wittelsbachers und forderte ihn auf, gleichermaßen zu handeln. Auch wenn Albrecht versuchte, sich mit Hinweis auf seine Neutralität als Vermittler aus der Affäre zu ziehen, war an eine fortgesetzte Nichtanerkennung der Königswürde Podiebrads nun endgültig nicht mehr zu denken. Andernfalls wären sowohl die Verhandlungsziele der Hohenzollern und Wettiner in weite Ferne gerückt, während Böhmen sich bei den bevorstehenden Konflikten im Reich auf die Seite der Wittelsbacher zu stellen drohte.

42. Hintergrund waren durch Herzog Wilhelm von Sachsen begonnenen Verhandlungen mit Frankreich um seine ererbten Ansprüche auf das Herzogtum Luxemburg, wozu der Markgraf ihm einen seiner gelehrten Räte geliehen hatte. Die Böhmen sahen in diesen Verhandlungen eine schwere Verletzung ihrer Rechte, weil Luxemburg ihrer Auffassung nach immer noch ein böhmisches Kronland war.

43. Wörtlich soll Podiebrad ausgerufen haben: Darczu hast du, herre von Brandemburg, dinen doctor gelihen, das $d u$ vnbillich tust, nach dem du der Cronen vnd vns gewand seyst (TRESP, Fürstentreffen, Editionsanhang Nr. 2). Die Verwendung der persönlichen Anrede „du“ war unter Fürsten unüblich und eine grobe Unhöflichkeit, die sich der König jedoch als Ranghöherer gegenüber dem Markgrafen erlauben konnte und deshalb nicht zu Konsequenzen führen musste.

44. Dies nach dem Bericht der sächsischen Räte an Herzog Wilhelm. Dem Bericht der bayerischen Räte zufolge hatte Lysura bereits am 10. April vor König Georg eine Rede gleichen Inhalts gehalten. Falls sich also entweder die bayerischen oder die sächsischen Räte nicht im Datum geirrt haben sollten, scheint es zweimal zu dieser öffentlichen Bekundung der Anerkennung Podiebrads und des Wunsches nach Wiederaufnahme des Bündnisses durch die Pfälzer gekommen zu sein. Möglicherweise wurde die dazwischen liegende Nacht noch einmal zur Beratung über Vertragsdetails genutzt, bevor es zur endgültigen verbalen Bestätigung der geplanten pfälzisch-böhmischen Einung kam, die dann am 15. April besiegelt wurde. 
Über den weiteren Verlauf des Egerer Fürstentreffens lassen sich mangels Quellen nur noch Vermutungen anstellen. Markgraf Albrecht von Brandenburg fügte sich in das Unvermeidliche und erkannte Georg von Podiebrad endgültig als König von Böhmen an. Darin folgten ihm auch bald die Wettiner. Spätestens ab dem 19. April 1459, und damit eine knappe Woche vor dem endgültigen Friedensschluss, bezeichnete Herzog Wilhelm von Sachsen Georg von Podiebrad als „König“. ${ }^{45}$ Andererseits dürfte der böhmische König diesen Sinneswandel seiner bisherigen Hauptgegner wiederum für sein politisches Spiel instrumentalisiert haben - diesmal als Druckmittel gegen Kurfürst Friedrich von der Pfalz. Inzwischen waren dessen Bemühungen um Einbeziehung Herzog Ludwigs von Bayern-Landshut in das geplante böhmisch-pfälzische Bündnis in erhebliche Schwierigkeiten geraten, die das anfängliche Einvernehmen zwischen Podiebrad und Kurfürst Friedrich trübten. ${ }^{46}$ Am 15. April zogen die Pfälzer schließlich aus Eger ab, wo sie nicht mehr erreicht hatten als ein relativ kraftloses Bündnis mit Böhmen, das die bayerischen Wittelsbacher nicht berücksichtigte.

Nachdem Friedrich von der Pfalz das Fürstentreffen von Eger verlassen hatte, konnte auch der sächsisch-böhmische Ausgleich vorangebracht werden. Am 17. April meldete Markgraf Albrecht von Brandenburg dem auf einer nahen Burg wartenden Herzog Wilhelm von Sachsen den nahenden Vertragsabschluss und forderte ihn auf, nun auch selbst nach Eger zu kommen. Von dem Empfang dort berichtet ein Brief Wilhelms an seinen älteren Bruder, Kurfürst Friedrich von Sachsen. ${ }^{47}$ Er verlief in ähnlicher Weise wie der des Pfälzer Kurfürsten eine Woche zuvor. Podiebrad sandte ihnen ein Ehrengeleit böhmischer Adeliger entgegen. Als der Wettiner dann gemeinsam mit dem Markgrafen vor der Stadt erschien, kam ihnen der König selbst mit großem Gefolge entgegen geritten. Alle drei Fürsten stiegen von den Pferden und begrüßten sich herzlich. Dann fand wieder ein ritterlicher Schaukampf statt, dem der festliche Einzug in die Stadt folgte. Wilhelm und Albrecht geleiteten den König daraufhin zu seiner Herberge und begaben sich dann in ihre Unterkünfte. Im Vergleich zum ersten Empfang des Markgrafen zeigte sich in diesem freundlichen Verhalten Podiebrads deutlich, dass sich das gegenseitige Verhältnis bereits entspannt hatte. Seine Ziele hatte er offenbar erreicht: Er war als böhmischer König von den deutschen Fürsten voll anerkannt worden und hatte mit diesen vorteilhafte dynastische Verbindungen verabredet, die seiner Familie dauerhaft den Fürstenstand sichern sollten. ${ }^{48}$

45. Tresp, Fürstentreffen, Editionsanhang Nr. 3.

46. SCHWARZ, Wittelsbacher, S. 234-238; MüLLER, Kärrnerarbeit, S. $182 \mathrm{f}$.

47. Tresp: Fürstentreffen, Editionsanhang Nr. 4.

48. Zu den Zielen Podiebrads und den Ergebnissen der Verhandlungen zwischen Böhmen, Brandenburg und Sachsen siehe Tresp, Fürstentreffen, S. 103-108; DERS.: «Erbeinung und Dynastie. Die Egerer Verträge von 1459 als Grundlage der sächsisch-böhmischen Beziehungen im 15. und 16. Jahrhundert», in: Blätter für deutsche Landesgeschichte 144 (2008), S. 55-85; MüLlER, Kärrnerarbeit, S. 183-192. 
Ein bescheidener Gastgeber: Das Treffen mit König Kasimir von POLEN (1462)

Nur kurz soll abschließend noch ein weiteres Beispiel angesprochen werden, weil es besonders aufschlussreich dafür zu sein scheint, wie geschickt Georg von Podiebrad die Klaviatur der symbolischen Kommunikation zu spielen wusste, um seine Widersacher nachgiebig zu stimmen. Es geht um sein erstes persönliche Zusammentreffen mit König Kasimir IV. von Polen im Mai 1462 in der schlesischen Stadt Glogau ${ }^{49}$ Die politische Konstellation, die zu diesem Treffen führte, braucht hier nur knapp umrissen zu werden. Es ging vordergründig um die Regelung der polnisch-böhmischen Nachbarschaft, die Klärung umstrittener Ansprüche in Schlesien und um eine mögliche Vermittlerrolle des böhmischen Königs im Konflikt zwischen Polen und dem Deutschen Orden in Preußen. Aber auch die Frage des böhmischen Königtums spielte eine - allerdings untergeordnete - Rolle. Trotz vorheriger politischer Annäherung hatte König Kasimir Georg von Podiebrad noch nicht offiziell als König von Böhmen anerkannt. Strittig war vor allem die Frage der Erbrechte sowie des noch ausstehenden Heiratsgutes von König Kasimirs Gemahlin Elisabeth von Habsburg, einer Schwester von Georgs Vorgänger Ladislaus Postumus. Zudem bestanden im einflussreichen polnischen Klerus immer noch Vorbehalte gegenüber den hussitischen Ketzern in Böhmen und ihrem "Hussitenkönig“.

Soweit es aus den zeitgenössischen Berichten erkennbar ist, scheint das Glogauer Herrschertreffen in den dafür üblichen Bahnen verlaufen zu sein. ${ }^{50}$ Zum verabredeten Termin sandte Podiebrad, der auch hier wieder Gastgeber war, dem polnischen König eine hochrangige Delegation böhmischer Adeliger entgegen, die ihn nach Glogau geleiteten. Etwa eine Meile vor der Stadt erwartete dann der böhmische den polnischen König. Beide Könige grüßten sich feierlich, ohne dabei vom Pferd zu steigen - man begegnete sich also auf Augenhöhe und damit im gleichen Rang. Anschließend zog man gemeinsam in die Stadt Glogau ein. Dort wurde Kasimir im Schloss einquartiert, während Georg im Rathaus logierte. Es folgten zwölftägige Beratungen und ein dicht gefülltes Festprogramm, bevor es am Morgen des 30. Mai zur freundlichen Verabschiedung zwischen den Königen kam, bei denen sie kleine Geschenke austauschten.

49. Dazu ausführlich aus polnischer Sicht Roman Heck, Zjazd Głogówski w 1462 r. (Acta Universitatis Wratislaviensis, Historia /), Warszawa/Wrócław, 1962. Siehe auch Čornej/BARTLová, Velké dějiny, S. 207; Heymann, George of Bohemia, S. 295-299; Urbánek, Věk poděbradský, Bd. 4, S. 540-545.

50. Die wichtigsten schlesischen Quellen dafür sind: Peter Eschenloer, Geschichte der Stadt Breslau, hg. von Gunhild Roth (Quellen und Darstellungen zur schlesischen Geschichte 29), Bd. 1, Münster, 2003 , S. 370 f.; Annales Glogoviensis, hg. von Hermann Markgraf (Scriptores Rerum Silesiacarum 10), Breslau, 1877, S. 15. Von polnischer Seite berichtet der Hofchronist Jan Długosz: Joannis Dlugossii Annales seu cronicae incliti regni Poloniae, Bd. 12, hg. von Krzysztof BACzKowski, Kraków, 2005, S. 31-33. 
Von allen diesen Vorgängen kennen wir so gut wie keine Details. Interessant sind aber zwei Dinge: Die Beobachter, in diesem Fall die schlesischen Chronisten aus Glogau und Breslau, berichten übereinstimmend, dass der Auftritt des polnischen Königs, der mit 5000 Reitern nach Glogau kam, den des böhmischen Königs, der nur 2000 Reiter im Gefolge hatte, deutlich an Pracht und Ausstattung übertraf. Und der polnische Chronist Jan Długosz berichtet weiter, dass König Kasimir am dritten Tag für die Böhmen ein besonders prachtvolles Fest veranstaltete. Da Podiebrad sich nicht in der Lage sah, etwas Vergleichbares zu bieten, habe er - so Długosz - sogar auf eine Gegeneinladung der Polen verzichtet. Sicher wird man davon ausgehen müssen, dass der polnische Hofhistoriograph die Intentionen Podiebrads hier nicht ganz korrekt wiedergab, um seinen eigenen Herrn in umso hellerem Licht erstrahlen zu lassen. Dennoch scheint sich damit anzudeuten, dass Georg von Podiebrad dem polnischen König in Glogau weitgehend die Bühne der öffentlichen Repräsentation überließ, obwohl er selbst als Gastgeber des Herrschtreffens große Möglichkeiten - eigentlich sogar die Pflicht - zur eigenen Inszenierung gehabt hätte. Man wird den Verzicht auf Selbstdarstellung nur als bewusst herbeigeführte zeremonielle Asymmetrie im Interesse der Politik deuten können. ${ }^{51}$ Vermutlich wollte er sich König Kasimir geneigter machen, indem er sich ihm nicht gleichrangig oder gar überlegen präsentierte, sondern sich ihm in seinem ganzen Auftreten unterordnete. Das zufriedene Urteil des Jan Długosz, das sicher auch die Meinung des polnischen Herrschers und seines Hofes widerspiegelt, spricht dafür, dass dies auch gelungen ist. Offenbar tat dies der Verhandlungsatmosphäre gut: Der Glogauer Tag jedenfalls führte zu deutlich verbesserten Beziehungen zwischen Polen und Böhmen.

\section{FAzIT}

Die persönlichen Treffen des böhmischen Königs Georg von Podiebrad mit verschiedenen Nachbarfürsten zu Beginn seiner Herrschaft markieren wichtige Etappen der Anerkennung seines Königtums. Dabei profitierte er erheblich von seiner faktischen Machtstellung durch das Kriegspotential Böhmens, das ihn zum gefürchteten Gegner und gesuchten Bündnispartner machte. Nur unter diesen Voraussetzungen konnte Kaiser Friedrich III. 1458 zu einem persönlichen Treffen mit dem Aufsteiger und zur Kompromissbereitschaft bewegt werden, ließen sich die deutschen Fürsten in Eger 1459 zur Akzeptanz seiner Dominanz und Königsherrschaft zwingen. Das begann in diesen Fällen schon bei der Gestaltung der Begrüßungsrituale, in denen der noch nicht anerkannte Georg von Podiebrad von seinen Gegenspielern bereits wie ein böhmischer König behandelt werden musste. In einer starken Position

51. Vgl. dazu die Überlegungen von SCHENK, Friedrich III., S. 137 über das gegensätzliche Verhalten Herzog Karls des Kühnen von Burgund in Metz und Trier, 1473. 
befand sich Podiebrad auch 1462 in Glogau. Sein Gast, der polnische König, war gleichzeitig in einen Kräfte zehrenden Krieg mit dem Deutschen Orden verwickelt und konnte sich keine Konfrontation mit Böhmen leisten.

Angesichts dieser Tatsachen sollte die Rolle der symbolischen Kommunikation oder der virtuose Umgang mit den ritualisierten Formen öffentlicher Herrschaftsinszenierungen nicht einseitig überbetont werden. Dennoch ist es bemerkenswert, wie geschickt Georg von Podiebrad auf den behandelten Herrschertreffen agierte. Er spielte seine politischen Trümpfe nicht offensiv aus. Er nutzte die Gelegenheit nicht zu einer Demonstration seiner Überlegenheit und daraus resultierender Machtansprüche. Gegenüber Ranghöheren wie dem Kaiser oder dem polnischen König verzichtete er weitgehend auf prunkvolle Selbstdarstellung und aufwendige Inszenierung eigener Ambitionen. Ein derartiges Verhalten wurde honoriert. Offenbar bereitwillig gaben seine Gegenüber ihre Vorbehalte auf und erkannten das böhmische Königtum des Georg von Podiebrad an. Lediglich Kaiser Friedrich III. erwies sich als überlegener Taktiker, vermied zunächst jede Eindeutigkeit und ließ sich den politischen Spielraum gegenüber Böhmen noch nicht nehmen.

Ein Meisterstück gelang dem umstrittenen böhmischen König aber gewiss in Eger, im April 1459. Das in aller Öffentlichkeit geschickt inszenierte Wechselspiel von Nähe und Distanz zwischen Georg von Podiebrad und den verschiedenen Reichsfürsten führte innerhalb kürzester Zeit dazu, dass der adlige Aufsteiger das politische Geschehen dominieren konnte. Bedeutende Fürstenhäuser wie die Wettiner und Hohenzollern, die ihn zuvor noch wegen seiner mangelnden Legitimität offen angefeindet hatten, waren daraufhin gezwungen, ihn vorbehaltlos zu akzeptierten und seine Familie in ihre dynastischen Kreise aufnehmen. 